\title{
Prevalence of ischaemic heart disease in middle aged British men
}

\author{
A G SHAPER, D G COOK, M WALKER, P W MACFARLANE` \\ From the Department of Clinical Epidemiology and General Practice, Royal Free Hospital School of Medicine, \\ London; and the ${ }^{\star}$ University Department of Medical Cardiology, Royal Infirmary, Glasgow
}

SUMMARY The prevalence of ischaemic heart disease was determined by an administered questionnaire and electrocardiography in 7735 men aged 40-59 years drawn at random from general practices in 24 British towns. Overall, one quarter of these men had some evidence of ischaemic heart disease on questionnaire or electrocardiogram or both. On questionnaire, $14 \%$ of men had possible myocardial infarction or angina, with considerable overlap of the two syndromes. The prevalence of possible myocardial infarction combined with angina and of definite angina only showed a fourfold increase over the age range studied.

Electrocardiographic evidence of ischaemic heart disease (definite or possible) was present in $15 \%$ of men, there being myocardial infarction in $4.2 \%$ and myocardial ischaemia in $10.3 \%$. Electrocardiographic evidence of myocardial infarction increased fourfold over the age range studied. There was considerable overlap of questionnaire and electrocardiographic evidence of ischaemic heart disease. Nevertheless, more than half of those with possible myocardial infarction combined with angina had no resting electrocardiographic evidence of ischaemic heart disease, and half of those with definite myocardial infarction on electrocardiogram had no history of chest pain at any time. This national population based study strongly suggests that the prevalence of ischaemic heart disease in middle aged British men is greater than has been indicated by previous studies based on occupational groups.

Ischaemic heart disease is a major cause of incapacity and death in middle aged and elderly men and women in Great Britain. There are reasonably sound data on deaths due to ischaemic heart disease ${ }^{1}$ but less information regarding its prevalence-that is, the proportion of people in the community with symptoms or signs of ischaemic heart disease or both. Several major prevalence studies of ischaemic heart disease have been carried out, usually based on one geographic $\mathrm{area}^{2}$ and often restricted to one occupational group. ${ }^{3}$ It is difficult to generalise from such studies to the British population at large, as there are considerable geographic and socioeconomic variations in cardiovascular disease mortality. ${ }^{4-6}$ Information from heart attack registers suggests that these variations affect non-fatal as well as fatal ischaemic heart disease

Requests for reprints to Professor A G Shaper, Department of Clinical Epidemiology and General Practice, Royal Free Hospital School of Medicine, Rowland Hill Street, London NW3 2PF.

Accepted for publication 10 January 1984 events, and thus the prevalence of the disease is likely to show as much geographic variation as its mortality. ${ }^{78}$ The British Regional Heart Study is concerned with such geographic variations in cardiovascular disease and includes a survey of middle aged men in 24 British towns. ${ }^{910}$ The present report, based on the findings of this study, describes the overall prevalence of ischaemic heart disease as determined by an administered questionnaire and electrocardiography. A companion report ( $p$ 606) analyses the ability of subjects in this study to recall a diagnosis of ischaemic heart disease made by a doctor. ${ }^{11}$ Further reports will deal with the effects of social class and town of residence on the prevalence of ischaemic heart disease and with the relation between its prevalence and those factors which might contribute to the development of the disorder.

\section{Subjects and methods}

The British Regional Heart Study includes 7735 men aged 40-59 years randomly selected from the age-sex 
registers of group general practices in 24 towns in England, Wales, and Scotland. The criteria for selecting the town, the general practice, and the subjects, as well as the methods of data collection, have been reported previously. ${ }^{10}$ In brief, the 24 towns were primarily selected from those with populations of $50000-100000$ (1971 Census). They were chosen to represent the full range of cardiovascular disease mortality and included towns in all the major standard regions. The general practice selected in each town was required to have a social class distribution representative of the men of that town.

From each age-sex register some 420 men aged 40-59 years were selected at random to produce fiveyear age groups of equal size. The list of names was reviewed by the doctors in the practice, who were asked to exclude those whom they considered could not participate because of severe mental or physical disability. It was emphasised that no attempt should be made to exclude subjects with cardiovascular problems, and close scrutiny of the returned annotated lists reduced the exclusions to approximately 6 to 10 per practice. The remaining subjects were invited to take part in the study in a letter signed by their general practitioner, and on average $78 \%$ of those invited attended for examination.

A mobile research team of three nurses administered to each man an extensive questionnaire which included questions on chest pain and medical history. The questions on chest pain were based on the WHO questionnaire, ${ }^{12}$ but they are not identical. Copies of the questionnaire are available on request. Electrocardiograms were recorded in analogue form on magnetic tape using the three orthogonal leads as derived from the modified axial lead system. ${ }^{13}$ They were simultaneously reviewed on an oscilloscope in order to detect major acute abnormalities, which were reported to the general practitioner. The completed tapes for each town were sent to the collaborating centre in Glasgow for replay to a computer system for analysis and interpretation. ${ }^{14} 15$ On those occasions $(n=400)$ when technical problems occurred with the recording 12 lead electrocardiograms were obtained on a Hewlett Packard (1515-B) machine and sent to the centre for visual analysis.

\section{TERMINOLOGY}

The prevalence of ischaemic heart disease was measured in several ways in this study. In order to make it clear which method is being referred to at any particular time the suffixes (Q) and (ECG) are used whenever necessary to refer respectively to the questionnaire on chest pain and to the electrocardiographic findings. Each of these two methods of determining prevalence has a variable level of certainty, which may be expressed by terms such as "definite" or "possible." As the clinical diagnosis of angina is based on symptoms it seems reasonable to apply these two grades of diagnostic certainty to the information elicited by administered questionnaire. On the other hand, the diagnosis of myocardial infarction is usually based on symptoms or signs or both (for example, enzyme response, electrocardiographic changes), and it thus seems inappropriate to use the term "definite myocardial infarction" when referring purely to a response to a question about prolonged severe chest pain. We, therefore, use the term "possible myocardial infarction (Q)" for the category of greatest certainty. This is well established in epidemiological use. ${ }^{12}$ In electrocardiography, where precise measurements and criteria are used, it is reasonable to use the terms "definite" and "possible." Definite angina (Q) and possible angina and myocardial infarction (Q) may be combined as ischaemic heart disease $(\mathrm{Q})$. The electrocardiographic findings of myocardial infarction (definite or possible) and myocardial ischaemia (definite or possible) may be combined as ischaemic heart disease (ECG). The term "ischaemic heart disease" without a suffix is used in the general sense.

\section{CRITERIA AND CATEGORIES \\ Myocardial infarction (Q)}

Possible myocardial infarction (Q) -Subjects were regarded as having had a possible myocardial infarction if $(a)$ they answered yes to "Have you ever had a severe pain in your chest lasting for half an hour or more?" and $(b)$ the distribution of pain included positions 4 or 5 or 8 (Fig. 1). They were also asked whether they had seen a doctor because of this pain.

Other prolonged severe chest pain-The subject answered yes to the above question, but the distribution of the pain did not include position 4 or 5 or 8 . They

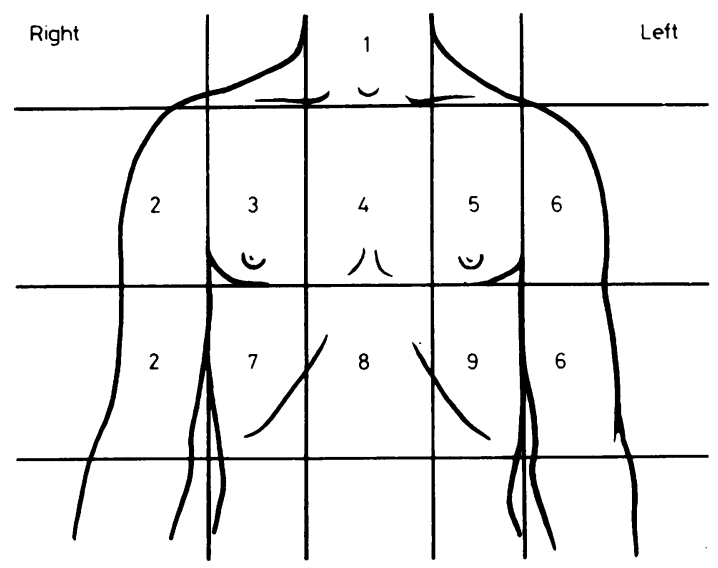

Fig. 1 Diagram showing sites of chest pain. 
were also asked whether they had seen a doctor because of this pain.

No prolonged severe chest pain.

\section{Angina (Q)}

Definite angina $(Q)$-The questions relating to angina followed the inquiry into severe chest pain. Subjects were regarded as having definite angina if they answered yes to $(a)$ "Do you ever have any pain or discomfort in your chest?" and (b) "When you walk uphill or hurry, does this produce pain?"; in addition, four additional criteria had to be satisfied: (i) the distribution of pain included position 4 or 5 or 8 ; (ii) the subject slowed down or stopped walking when the pain occurred; (iii) the pain went away if he stood still and (iv) did so in less than 10 minutes. These criteria denote definite angina grade 1 . If, in addition, the chest pain was produced by walking at an ordinary pace on the level it was regarded as grade 2. Four subjects with chest pain on the level, but not on walking uphill or hurrying, were included in grade 1 as they satisfied all the four additional criteria.

Possible angina (Q)-Chest pain was present on exertion (walking uphill or hurrying) but did not fulfil all four of the additional criteria. Possible angina was also separated into grades 1 and 2 . Nine of these subjects said they had chest pain on the level but not on walking uphill or hurrying and were included in grade 1.

Chest pain (not on exertion) - The subject answered yes to the question "Do you ever have any pain or discomfort in your chest?" but it was not related to exertion.

\section{No chest pain.}

\section{Electrocardiogram}

Details of the criteria used in interpreting the three orthogonal lead electrocardiogram have already been published. ${ }^{14-16}$ In the following sections an explanation is given of the system of classification used in this study, and an outline is offered of possible relations between this system and the Minnesota Code, ${ }^{12}$ which is widely used for classifying the 12 lead electrocardiogram. It must be emphasised that the comparison can be only an approximation. For the purposes of this study, a system of exclusive categories is used in ranking order so that each man can appear once only in the analysis of findings.

Myocardial infarction (ECG)-In the three orthogonal lead electrocardiogram the diagnosis of myocardial infarction is made on the basis of a broad $Q$ wave in any of the leads together with a $Q: R$ amplitude ratio greater than $1 / 3$ if the $Q$ wave is in the anterolateral $(\mathrm{X})$ or inferior $(\mathrm{Y})$ leads. The anteroseptal (Z) lead of the three orthogonal lead electrocardiogram in this system should be considered equival- ent to lead V2 or V3. Q and QS patterns are expressed as definite or possible myocardial infarction, depending on the width of the $Q$ wave and the magnitude of the $Q: R$ amplitude ratio. The Minnesota Code classifies $Q$ and $Q S$ patterns using varying criteria for anterolateral, inferior, and anterior sites. These equate almost on a one-to-one basis with the three orthogonal lead electrocardiogram-namely, X anterolateral, $\mathrm{Y}$ inferior, and $\mathrm{Z}$ anteroseptal. If changes occur in leads $\mathrm{X}$ and $\mathrm{Z}$ the infarct is regarded as anterior. In this study definite myocardial infarction (three lead) equates essentially with Minnesota Code 1.1 and most of $1.2(1.2 .1$ and 1.2.2). Possible myocardial infarction (three lead) basically equates with Minnesota Code 1.2.7/8 and 1.3.

Myocardial ischaemia (ECG)-A combination of ST segment and $T$ wave changes in the three lead electrocardiogram is used to report myocardial ischaemia. Although the Minnesota Code treats the ST segment and $\mathrm{T}$ wave separately, there are considerable similarities between the three and 12 lead coding schemes. As with infarction, three basic areas are identified, and the degree of certainty of diagnosis is related either to the amount of ST depression or to the extent of $T$ wave negativity or low positivity. The major difference between the system would be that the Minnesota Codes 4.1 and 5.1 require more ST depression or $\mathrm{T}$ wave negativity to be present than the criteria used for the three orthogonal lead electrocardiogram. For example, Minnesota Code 4.1.2 requires ST junctional depression in excess of $0.1 \mathrm{mV}$, whereas the three orthogonal lead system requires ST depression in excess of $0.06 \mathrm{mV}$ for a report of definitely abnormal ST segment, in addition to requiring the ST segment to be flat or downward sloping. Thus a three lead electrocardiogram regarded as showing definite myocardial ischaemia equates with Minnesota Code 4.1 or 5.1 , whereas those three lead electrocardiographic appearances regarded as possible myocardial ischaemia equate with Minnesota Codes $4.1,4.2,5.2$, and 5.3.

Other categories-These are not dealt with in detail in this report. The major conduction defects correspond completely in the three orthogonal and the 12 lead electrocardiograms. In the present study the presence of left bundle branch block is regarded as evidence of possible myocardial ischaemia. Atrial fibrillation and certain atrioventricular conduction defects are not regarded as evidence of myocardial ischaemia, although this has been done in some other studies. Ventricular hypertrophy is not regarded as evidence of ischaemic heart disease and will be reported in detail in later publications concerned with blood pressure and hypertension. $T$ wave abnormalities occurring in the anterolateral lead $\mathrm{X}$ in the presence of left ventricular hypertrophy (that is, the so called left ven- 
tricular strain pattern) were subsumed in the electrocardiographic diagnosis of left ventricular hypertrophy and not reported separately as "myocardial ischaemia."

\section{Results}

POSSIBLE MYOCARDIAL INFARCTION (Q)

A history of prolonged severe chest pain in an appropriate site, such as might occur in acute myocardial infarction, was recorded in 706 men-that is, $9.1 \%$ of all men had possible myocardial infarction (Q). A similar chest pain occurring in an inappropriate site, predominantly site 9 , was recorded in a further 80 men-that is, $1.0 \%$ of all men.

\section{ANGINA (Q)}

One third (2582) of the men admitted to having chest pain at some time, and in one quarter (607) of these the chest pain was related to exertion (Fig. 2). Definite angina was present in 367 men (307 grade 1, 60 grade 2)-that is, $4.8 \%$ of all men. Possible angina was present in a further 240 men (205 grade 1, 35 grade 2) - that is, $3 \cdot 1 \%$ of all men. Two thirds of those with possible angina (158/240) satisfied three of the four additional criteria. In both definite and possible categories there were five to six times as many men with grade 1 as with grade 2 angina.

\section{POSSIBLE MYOCARDIAL INFARCTION (Q) AND ANGINA (Q)}

It was possible for the men to respond independently to the questions on possible myocardial infarction and angina, and Table 1 shows the relation between responses to these two areas of inquiry.

The men with a history of possible myocardial infarction were far more likely to have angina (definite or possible) than those with no such history $(31 \% v$ $5 \%)$. Those with "other" severe chest pain - that is, in an inappropriate site-had an intermediate frequency of angina (14\%). Similarly, men with angina (definite or possible) were far more likely to have a

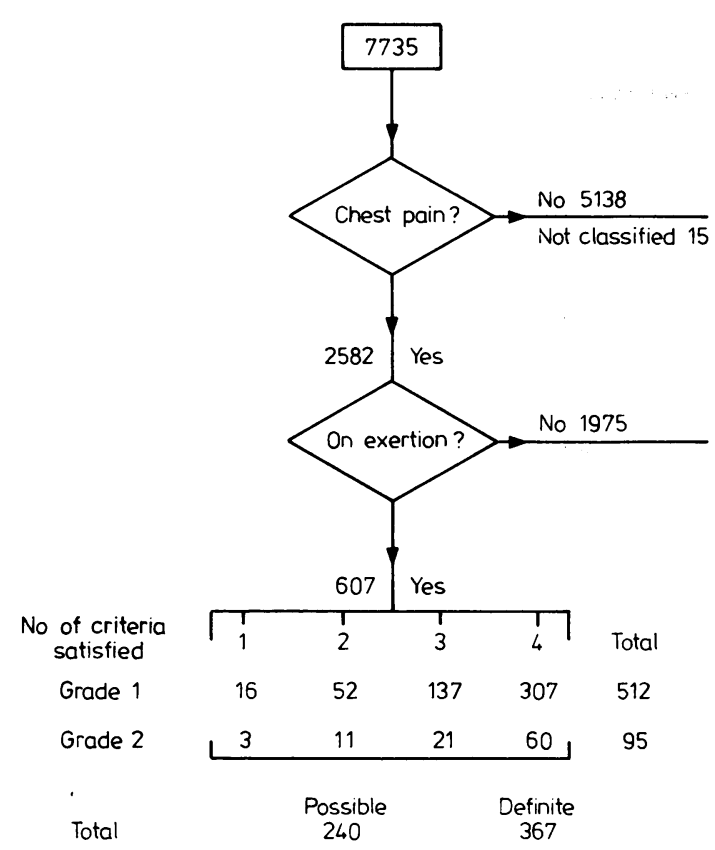

Fig. 2 Flow chart showing response to questions on chest pain (angina) from 7735 subjects.

history of possible myocardial infarction than those with no chest pain $(32-47 \% v 6 \%)$. Those with nonexertional chest pain had a frequency of possible myocardial infarction ( $9 \%$ ) similar to that seen in men without angina. It is important to note that men with possible angina have rates of possible myocardial infarction similar to those observed in men with definite angina. Overall, 1094 (14.2\%) men had some evidence of ischaemic heart disease on questionnaire, and Table 2 summarises the information in Table 1 .

\section{ELECTROCARDIOGRAPHIC EVIDENCE OF}

ISCHAEMIC HEART DISEASE

The exclusive ranking system of determining the elec-

Table 1 Relation between angina (Q) and possible myocardial infarction (Q). Figures are numbers of subjects

\begin{tabular}{|c|c|c|c|c|c|}
\hline $\begin{array}{l}\text { Questionnaire } \\
\text { categories }\end{array}$ & $\begin{array}{l}\text { Possible myocardial } \\
\text { infarction }\end{array}$ & $\begin{array}{l}\text { "Other" severe } \\
\text { chest pain }\end{array}$ & $\begin{array}{l}\text { No severe } \\
\text { chest pain }\end{array}$ & $\begin{array}{l}\text { Total } \\
\text { No }\end{array}$ & $\begin{array}{l}\% \text { With possible } \\
\text { myocardial infarction }\end{array}$ \\
\hline $\begin{array}{l}\text { Definite angina } \\
\text { Grade } 2 \\
\text { Grade } 1 \\
\text { Possible angina }\end{array}$ & $\begin{array}{r}28 \\
109\end{array}$ & $\begin{array}{l}0 \\
2\end{array}$ & $\begin{array}{r}32 \\
196\end{array}$ & $\begin{array}{r}60 \\
307\end{array}$ & $\begin{array}{l}47 \\
36\end{array}$ \\
\hline $\begin{array}{l}\text { Grade } 2 \\
\text { Grade } 1 \\
\text { Chest pain (not on exertion) } \\
\text { No chest pain }\end{array}$ & $\begin{array}{r}14 \\
65 \\
181 \\
306\end{array}$ & $\begin{array}{r}2 \\
7 \\
24 \\
45\end{array}$ & $\begin{array}{r}19 \\
133 \\
1770 \\
4786\end{array}$ & $\begin{array}{r}35 \\
205 \\
1975 \\
5137\end{array}$ & $\begin{array}{r}40 \\
32 \\
9 \\
6\end{array}$ \\
\hline Total & 703 & 80 & 6936 & $7719 \star$ & 9 \\
\hline$\%$ With angina (definite/possible) & 31 & 14 & 5 & 8 & - \\
\hline
\end{tabular}

*Data missing on possible myocardial infarction in one subject and on angina in 15 . 
Table 2 Ischaemic heart disease on questionnaire and electrocardiography

\begin{tabular}{|c|c|c|}
\hline & No & $\%$ \\
\hline \multicolumn{3}{|c|}{ Questionnaire } \\
\hline \multirow{2}{*}{$\begin{array}{l}\text { Possible myocardial infarction and } \\
\text { angina } \\
\text { Possible myocardial infarction only } \\
\text { Angina only } \\
\text { Definite } \\
\text { Possible } \\
\text { Ischaemic heart disease (Q) }\end{array}$} & $\begin{array}{l}216 \\
487\end{array}$ & $\begin{array}{l}2.8 \\
6.3\end{array}$ \\
\hline & $\begin{array}{r}230 \\
161 \\
1094\end{array}$ & $\begin{array}{r}3.0 \\
2.1 \\
14.2\end{array}$ \\
\hline \multicolumn{3}{|c|}{ Electrocardiography $\dagger$} \\
\hline $\begin{array}{l}\text { Definite } \\
\text { Possible }\end{array}$ & $\begin{array}{r}242 \\
86\end{array}$ & $\begin{array}{l}3 \cdot 1 \\
1 \cdot 1\end{array}$ \\
\hline $\begin{array}{l}\text { Myocardial ischaemia } \\
\text { Definite } \\
\text { Possible } \\
\text { Ischaemic heart disease (ECG) }\end{array}$ & $\begin{array}{r}257 \\
541 \\
1126\end{array}$ & $\begin{array}{r}3.3 \\
7.0 \\
14.6\end{array}$ \\
\hline
\end{tabular}

\section{$\star$ Definite or possible.}

+ECG evidence missing for eight subjects

trocardiographic status of each man (see methods) means that each individual can appear in only one category. Overall, $1126(14.6 \%)$ men were regarded as having evidence of ischaemic heart disease on the electrocardiogram (Table 2). Nineteen men with left bundle branch block are included in "possible myocardial ischaemia."

\section{ELECTROCARDIOGRAPHIC AND QUESTIONNAIRE EVIDENCE OF ISCHAEMIC HEART DISEASE}

There is considerable overlap between the electrocardiographic findings and the prevalence of possible myocardial infarction $(Q)$ and angina $(Q)$. Table 3 shows the proportion of those with symptoms of ischaemic heart disease on questionnaire who have electrocardiographic evidence of ischaemic heart disease. Those with possible myocardial infarction combined with angina $(Q)$ have the highest rate of elec- trocardiographic abnormalities (45\%), but even in this group of men, who are likely to have severe atherosclerosis and ischaemic heart disease, more than half have no resting electrocardiographic evidence of ischaemic heart disease. Men with possible myocardial infarction $(\mathrm{Q})$ only, definite angina $(\mathrm{Q})$ only, or possible angina $(\mathrm{Q})$ only have similar rates of ischaemic heart disease (ECG). Men with "other chest pain" (non-exertional chest pain or prolonged severe chest pain in an inappropriate site) have the same frequency of ischaemic heart disease (ECG) as those with "no chest pain."

Table 3 also shows the proportion of those with electrocardiographic abnormalities who have symptoms of ischaemic heart disease on administered questionnaire. Of those with definite myocardial infarction (ECG), $51 \%$ have a history of ischaemic heart disease (Q) - that is, almost half of these men give no history of severe chest pain at any time or of angina. The men with other electrocardiographic abnormalities (possible myocardial infarction, definite or possible myocardial ischaemia) have lower rates of positive response to the questionnaire. From the data in Table 3 , it can be calculated that men with any electrocardiographic evidence of ischaemic heart disease are more than twice as likely to respond positively to the chest pain questionnaire as those with no electrocardiographic evidence of ischaemic heart disease (315/ $1124(28 \%) v 778 / 6587(12 \%))$.

\section{OVERALL PREVALENCE OF ISCHAEMIC HEART}

DISEASE

From the detailed information in Table 3 a number of diagnostic categories relevant to the prevalence of ischaemic heart disease may be derived. At the one extreme there is a group of 49 men with definite myocardial infarction (ECG) together with question-

Table 3 Relation between the evidence for ischaemic heart disease (IHD) on electrocardiography and on questionnaire. Figures are numbers of subjects

\begin{tabular}{|c|c|c|c|c|c|c|c|c|}
\hline \multirow[t]{3}{*}{ Questionnaire } & \multicolumn{8}{|c|}{ Electrocardiography } \\
\hline & \multicolumn{2}{|c|}{ Myocardial infarction } & \multicolumn{2}{|c|}{ Myocardial ischaemia } & \multirow{2}{*}{$\begin{array}{l}I H D \\
(E C G)\end{array}$} & \multirow{2}{*}{$\begin{array}{l}\text { No IHD } \\
\text { (ECG) }\end{array}$} & \multirow{2}{*}{ Total } & \multirow{2}{*}{$\begin{array}{l}\% \text { With } \\
I H D(E C G)\end{array}$} \\
\hline & Definite & Possible & Definite & Possible & & & & \\
\hline $\begin{array}{l}\text { Possible MI and angina } \\
\text { Possible MI only } \\
\text { Definite angina only } \\
\text { Possible angina only } \\
\text { Other chest pain } \\
\text { No chest pain }\end{array}$ & $\begin{array}{r}49 \\
53 \\
13 \\
9 \\
33 \\
85\end{array}$ & $\begin{array}{r}7 \\
7 \\
4 \\
2 \\
18 \\
48\end{array}$ & $\begin{array}{r}24 \\
31 \\
12 \\
9 \\
55 \\
126\end{array}$ & $\begin{array}{r}18 \\
29 \\
31 \\
17 \\
111 \\
333\end{array}$ & $\begin{array}{r}98 \\
120 \\
60 \\
37 \\
217 \\
592\end{array}$ & $\begin{array}{r}118 \\
366 \\
170 \\
124 \\
1619 \\
4190\end{array}$ & $\begin{array}{c}216 \\
486 \\
230 \\
161 \\
1836+ \\
4782\end{array}$ & $\begin{array}{l}45 \\
25 \\
26 \\
23 \\
12 \\
12\end{array}$ \\
\hline Total & 242 & 86 & 257 & 539 & 1124 & 6587 & $7711^{\star}$ & 15 \\
\hline \% With IHD (Q) & 51 & 23 & 30 & 18 & 28 & 12 & 14 & - \\
\hline
\end{tabular}

MI, myocardial infarction.

*Data missing on possible infarction (Q) or angina (Q) in 16 subjects and ECG evidence missing on eight subjects

†Comprises those men with chest pain not on exertion (1770), severe chest pain in an inappropriate site (45), and those with both of these symptoms (24); missing ECG or questionnaire (3). 
Table 4 Prevalence of ischaemic heart disease by electrocardiographic (ECG) and questionnaire $(Q)$ categories. Figures are numbers of subjects

\begin{tabular}{lccc}
\hline & No & $\%$ & Total No (\%) \\
\hline ECG and Q & & & $315(4 \cdot 1)$ \\
ECG only & & & $809(10 \cdot 5)$ \\
$\quad \begin{array}{l}\text { Definite myocardial infarction } \\
\text { Possible MI or definite ischaemia }\end{array}$ & 118 & 1.5 & \\
$\begin{array}{l}\text { Possible ischaemia } \\
\text { only }\end{array}$ & 444 & 5.2 & \\
$\begin{array}{l}\text { Possible MI and angina } \\
\text { Possible MI or angina }\end{array}$ & 118 & 1.5 & $778(10 \cdot 1)$ \\
Total & 660 & 8.6 & \\
\hline
\end{tabular}

naire evidence of possible myocardial infarction and angina. At the other extreme are 333 men with possible myocardial ischaemia (ECG) and no history of any chest pain.

Overall, $1902(24.7 \%)$ of the men had some evidence of ischaemic heart disease by questionnaire or electrocardiography or both. The data in Table 4 are presented in a manner which allows prevalence to be viewed at several levels. In a prospective study of this kind we are concerned with the prognostic significance of all these categories, and even with other subcategories which may be derived from Table 3.

AGE AND THE PREVALENCE OF ISCHAEMIC HEART DISEASE

Questionnaire

The prevalence of possible myocardial infarction combined with angina and of definite angina only increase progressively with age, rising almost fourfold over the four successive five-year age groups (Table 5). Possible myocardial infarction only and

Table 5 Prevalence of various diagnostic categories of ischaemic heart disease by age group. Figures are percentages of subjects

\begin{tabular}{|c|c|c|c|c|}
\hline \multirow[b]{2}{*}{$\begin{array}{l}\text { Diagnostic } \\
\text { category }\end{array}$} & \multicolumn{4}{|c|}{ Age group (yr) } \\
\hline & $\begin{array}{l}40-44 \\
(n=1838\end{array}$ & $\begin{array}{l}45-49 \\
(n=1898)\end{array}$ & $\begin{array}{l}50-54 \\
(n=1974)\end{array}$ & $\begin{array}{l}55-59 \\
(n=2025)\end{array}$ \\
\hline $\begin{array}{l}\text { Questionnaire (Q): } \\
\text { Possible MI and angina } \\
\text { Possible MI only } \\
\text { Definite angina only } \\
\text { Possible angina only } \\
\text { Other chest pain }\end{array}$ & $\begin{array}{r}1.1 \\
4.5 \\
1.4 \\
1.5 \\
27.5\end{array}$ & $\begin{array}{r}2.2 \\
5.7 \\
2.2 \\
1.6 \\
26.2\end{array}$ & $\begin{array}{r}3.5 \\
7.7 \\
3.1 \\
2.6 \\
22.1\end{array}$ & $\begin{array}{r}4.2 \\
7.2 \\
5.1 \\
2.5 \\
20.0\end{array}$ \\
\hline $\begin{array}{l}\text { Electrocardiogram (ECG): } \\
\text { Myocardial infarction } \\
\text { Myocardial ischaemia }\end{array}$ & $\begin{array}{l}1.7 \\
8.8\end{array}$ & $\begin{array}{l}3 \cdot 3 \\
8 \cdot 1\end{array}$ & $\begin{array}{r}5 \cdot 2 \\
11 \cdot 2\end{array}$ & $\begin{array}{r}6.6 \\
12.9\end{array}$ \\
\hline $\begin{array}{l}\text { Combined: } \\
Q \text { or ECG } \\
Q \text { and ECG }\end{array}$ & $\begin{array}{r}17 \cdot 6 \\
2 \cdot 3\end{array}$ & $\begin{array}{r}21 \cdot 1 \\
3 \cdot 4\end{array}$ & $\begin{array}{r}28.0 \\
7.0\end{array}$ & $\begin{array}{r}31.2 \\
9.3\end{array}$ \\
\hline
\end{tabular}

MI, myocardial infarction. possible angina only do not show the same progressive increase in prevalence with age, although there is about a $50 \%$ increase in prevalence from the $40-49$ year age group to the 50-59 year age group. "Other chest pain" (non-exertional chest pain or severe chest pain in an inappropriate site) shows a small but progressive decline with increasing age.

\section{Electrocardiogram}

Myocardial infarction (definite and possible) increases progressively with age, with a fourfold rise in prevalence over the age range. Myocardial ischaemia shows only a small increase with age-namely, $8.5 \%$ below 50 years and $12 \cdot 1 \%$ in the $50-59$ year age group.

\section{Overall prevalence}

The overall prevalence of ischaemic heart disease, using electrocardiographic or questionnaire evidence, almost doubles over the age range covered in this study - that is, from $17 \cdot 6 \%$ to $31 \cdot 2 \%$. The percentage of men with both electrocardiographic and questionnaire evidence of ischaemic heart disease increases fourfold-that is, from $2.3 \%$ to $9.3 \%$. These findings suggest that not only is the overall prevalence increasing with age, but there is simultaneously a considerable and disproportionate increase in the proportion of men with severe ischaemic heart disease.

For the purposes of internal validation of the questionnaire, it is of interest to observe the proportion of subjects with some electrocardiographic evidence of ischaemic heart disease in each questionnaire category by age (ischaemic heart disease (ECG)) (Table 6). Men with possible myocardial infarction and angina (Q) show a high rate of ischaemic heart disease (ECG) in all age groups and a twofold increase from the youngest to the oldest group. The men with possible myocardial infarction (Q) only show rates of ischaemic heart disease (ECG) similar to the total study population in those under 50 years, but the rates of ischaemic heart disease (ECG) are considerably increased in the older subjects. For men with angina $(\mathrm{Q})$ only (definite and possible) the pattern of ischaemic heart disease (ECG) is similar to that seen for possible myocardial infarction $(\mathrm{Q})$ alone with a

Table 6 Percentage of men with electrocardiographic evidence of ischaemic heart disease in questionnaire categories by age

\begin{tabular}{|c|c|c|c|c|}
\hline \multirow[b]{2}{*}{$\begin{array}{l}\text { Diagnostic } \\
\text { category }\end{array}$} & \multicolumn{4}{|c|}{ Age range (yr) } \\
\hline & $\begin{array}{l}40-44 \\
(n=1838)\end{array}$ & $\begin{array}{l}45-49 \\
(n=1898)\end{array}$ & $\begin{array}{l}50-54 \\
(n=1974)\end{array}$ & $\begin{array}{l}55-59 \\
(n=2025)\end{array}$ \\
\hline 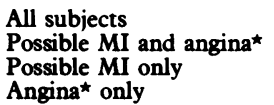 & $\begin{array}{l}10 \\
29 \\
14 \\
17\end{array}$ & $\begin{array}{l}11 \\
38 \\
13 \\
12\end{array}$ & $\begin{array}{l}16 \\
46 \\
26 \\
27\end{array}$ & $\begin{array}{l}20 \\
53 \\
38 \\
32\end{array}$ \\
\hline
\end{tabular}


considerable increase in the rate of ischaemic heart disease (ECG) in the men aged 50 years or more.

\section{Discussion}

The main purpose of the prevalence data from the Regional Heart Study is to provide the background for a prospective study of cardiovascular events taking place in these men. Such events can be related to the many variables measured at the original examination, including the usual "risk factors" and the prevalence criteria derived from the questionnaire and the electrocardiogram. They are also useful for exploring the relations between existing ischaemic heart disease in the men and their measured characteristics, as part of the search for causal factors. Furthermore, they may be used for assessing the present size of the problem of ischaemic heart disease in the community and for determining the facilities likely to be required by those affected by the disorder.

The reliability of the prevalence data depends almost entirely on the validity of the methods usedthat is, the questionnaire and the electrocardiogram. The questionnaire used in this study was originally developed for detecting the presence or absence of angina or a history of possible myocardial infarction in population studies and was not primarily intended for use on individual patients. ${ }^{17}$ Nevertheless, from the earliest days of assessing the significance of answers to the questionnaire it became clear that positive answers in population groups and individuals contributed to the prognosis as much as positive findings on electrocardiography. ${ }^{18}$ Rose and his colleagues interviewed 1136 men in 1961 using the standardised questionnaire and in 1962 they reinterviewed 995 of these men. ${ }^{18}$ The prevalence rates for angina were $3.3 \%$ in 1961 and $3.4 \%$ in 1962 , but the men who made up the totals were not the same in the two years. Although the vast majority of men were consistent in their replies on the two occasions ( $94 \%$ negative, $2 \%$ positive), approximately half of those with angina in 1961 (19/33) did not have angina in 1962, and half of those with angina in 1962 (14/32) had not had angina in 1961. Men with consistently positive answers for either angina or possible myocardial infarction in both 1961 and 1962 were more likely to have electrocardiographic changes of ischaemia than those whose answers were not consistent. Even those who answered positively one year and negatively the other year were more likely to have electrocardiographic changes than the men who gave consistently negative answers. There seems to be little doubt that this questionnaire is a powerful tool for detecting individuals and groups with ischaemic heart disease and at high risk of further episodes such as acute myocardial infarction or sudden death.

In an extended study of the same 1136 men based on four examinations over a four year period, the period prevalence of angina remained constant at around $4 \%$ but with a great deal of flux among the "angina positive" group. ${ }^{19}$ The majority were positive on only a single occasion. On follow up, however, $59 \%$ of the clinical coronary events had been preceded by a positive response to the questionnaire (angina or possible myocardial infarction) and $80 \%$ by either a positive questionnaire or a positive electrocardiogram. Relatively few of these earlier manifestations would have been recognised apart from the survey, and the physician in charge would have concluded that a major illness had occurred without prior warning. This makes for a particularly difficult situation in defining what is an "old" and a "new" case of ischaemic heart disease and suggests that the definition of incidence may be more arbitrary than is realised.

\section{POSSIBLE MYOCARDIAL INFARCTION (Q)}

The questionnaire administered to the 7735 men in the present study indicates that about 1 in 10 have experienced prolonged severe chest pain such as might occur in acute myocardial infarction. Men with such a history were five to six times as likely to have angina on questionnaire as men who had not experienced such chest pain and were five times as likely to have electrocardiographic changes of myocardial infarction or definite myocardial ischaemia. These findings strongly suggest that a high proportion of men with a history of possible myocardial infarction (Q) actually have ischaemic heart disease.

ANGINA (Q)

Chest pain is an extremely common symptom, but the criteria which have to be satisfied before a diagnosis of definite angina is made in this study are exacting. Possible angina appears to be very similar to definite angina in its association with possible myocardial infarction $(Q)$ and with evidence of ischaemic heart disease on electrocardiography. For the purposes of assessing the prevalence of angina in these men it therefore seems reasonable to combine the definite and possible categories as angina $(\mathrm{Q})$. About $8 \%$ of these middle aged men have angina and one in three of those with angina also have a history of possible myocardial infarction ( $Q$ ).

\section{ELECTROCARDIOGRAPHY}

The relation of electrocardiographic finding to the risk of ischaemic heart disease has been well documented. ${ }^{20} \mathrm{~A}$ recent review of three epidemiological studies in Chicago ${ }^{21}$ has shown that major electrocardiographic abnormalities retain a significant relation to mortality even when age, diastolic blood pressure, serum cholesterol concentration, relative weight, and cigarette smoking are taken into consideration. In two of these Chicago studies minor elec- 
trocardiographic changes also showed an independent relation to mortality. The electrocardiograms in these studies were classified using the Minnesota Code, a system originally developed during the 1950 s for use in epidemiological studies in order to provide for the "reporting of findings in uniform, clearly defined and objective terms with the least risk of confusion with regard to interpretation." 22 The orthogonal three lead systems developed in the 1960s considerably reduce the electrical distortion inherent in the conventional 12 lead electrocardiogram and by reduction of redundant information facilitate the analysis of electrocardiograms by computer. A classification system suitable for epidemiological investigations has recently been proposed ${ }^{23}$ but was not available at the time of this study.

A recent comparative study provides information on the validity of the three lead orthogonal systems in the diagnosis of ischaemic heart disease. ${ }^{24}$ In 90 patients undergoing coronary arteriography both three lead orthogonal and 12 lead electrocardiograms were used to examine ST-T wave abnormalities in relation to the presence of arterial obstruction. The $X$ lead (anterolateral) was compared with leads I, V5, and V6, the Y lead (inferior) with aVF and lead II, and the $\mathrm{Z}$ lead (anteroseptal) with V2 and V3 of the 12 lead electrocardiogram. The 12 lead electrocardiogram was interpreted by two cardiologists. The overall agreement between the two systems was relatively high. The three orthogonal lead system had a somewhat greater sensitivity than the 12 lead system, with a slightly lower specificity in the anteroseptal and inferior leads. Nevertheless, the predictive value was very similar for the two systems, about $80 \%$ for anterolateral leads, $86 \%$ for anteroseptal leads, and $90 \%$ for inferior leads.

It should perhaps be emphasised that both systems merely help to describe and categorise the electrocardiographic findings; they do not provide a diagnosis. It should also be emphasised that in this study the terms "definite" and "possible," as applied to myocardial ischaemia (ECG), essentially indicate the severity of the ST-T changes. It must also be remembered that an exclusive categorisation system was used and that secondary ST-T abnormalities such as occur in ventricular hypertrophy and right bundle branch block were not regarded as evidence of myocardial ischaemia (ECG). Furthermore, while ST-T change can be due to many causes, in the male population aged 40-59 years under study, none of whom was acutely ill, the most likely cause of a primary ST-T change is myocardial ischaemia.

When the men have been followed for the development of clinical ischaemic heart disease it will be possible to assign levels of risk to the various categories of electrocardiographic findings as in other studies. At present it is feasible only to report on the prevalence of the findings and their relation to the information obtained on questionnaire. It is of interest and concern that, of the 241 men with definite myocardial infarction on electrocardiograms, only half had a history of possible myocardial infarction or angina or both on questionnaire. This lends further support to the widely accepted concept of unrecognised (silent) myocardial infarction ${ }^{25}$ and emphasises the need for objective methods of determining the prevalence of ischaemic heart disease in populations and in assessing the cardiovascular status of individuals.

\section{COMPARISON WITH OTHER STUDIES}

It would be useful to compare the findings in a study of this kind with those derived from similar studies in the same population on previous occasions. Unfortunately, there are no similar studies based on subjects recruited from general practices spread widely over Great Britain, but there are two major studies which provide comparable data.

The Whitehall Study of cardiorespiratory disease and diabetes was based on 18403 male civil servants aged 40-64 years working in selected government departments within about two miles of Whitehall, London. ${ }^{326}$ The men were examined over a two and a half year period in 1967 to 1969 and the response rate was $77 \%$, ranging from $58 \%$ among messengers to $87 \%$ among senior grades. They completed a selfadministered questionnaire, which included questions on chest pain (possible myocardial infarction, angina), and had an electrocardiogram, in which only the six limb leads were recorded. The prevalence of ischaemic heart disease was expressed in terms of the presence of angina $(\mathrm{Q})$ and possible myocardial infarction (Q) and by Minnesota Code items indicative of myocardial ischaemia (1.1-1.3, 4.1-4.4, 5.1-5.3, 7.1).

The WHO Collaborative Trial in the Multifactorial Prevention of Coronary Heart Disease included a United Kingdom group (The UK Heart Disease Prevention Project (UKHDPP)) of 18210 men aged 40-59 years employed in 24 large industrial groups, mainly factories. 27 They represent a cross section of light, medium, and heavy industry. The study included all men regardless of their work activity and they were examined between 1971 and 1973 .

These two studies record similar prevalences of the various manifestations of ischaemic heart disease and both show a lower prevalence than the Regional Heart Study (Table 7). In the Regional Heart Study data (Table 7) angina (Q) includes possible angina, whereas this group may have been excluded in the Whitehall angina category. In both the Whitehall Study and the UKHDPP there is relatively little over- 
Table 7 Prevalence of ischaemic heart disease (IHD) in the Whitehall Study, ${ }^{26}$ the UK Heart Disease Prevention Project (UKHDPP), ${ }^{27}$ and the British Regional Heart Study (RHS). Figures are percentages of subjects

\begin{tabular}{lclc}
\hline $\begin{array}{l}\text { Diagnostic } \\
\text { category }\end{array}$ & $\begin{array}{c}\text { Whitehall } \\
(1967-9)\end{array}$ & $\begin{array}{l}\text { UKHDPP } \\
(1971-3)\end{array}$ & $\begin{array}{l}\text { RHS } \\
(1978-80)\end{array}$ \\
\hline Angina (Q) & 4.3 & 3.6 & 7.9 \\
Possible MI (Q) & 6.5 & 6.6 & 9.1 \\
IHD (Q) & 10.4 & - & 14.2 \\
IHD (ECG) major & $0.5 \star$ & 0.9 & 3.1 \\
IHD (ECG) other & 5.0 & 6.9 & 11.4 \\
Any suspect IHD & 14.1 & - & 24.7 \\
\hline
\end{tabular}

MI, myocardial infarction.

* Minnesota Code 1.1-1.2.

† Minnesota Code 1.1-1.3.

lap between a positive history on questionnaire and electrocardiographic evidence of ischaemic heart disease. In the UKHDPP $23 \%$ of those with angina (Q) and $5 \%$ of those with possible myocardial infarction (Q) had some electrocardiographic evidence of ischaemic heart disease. The corresponding figures for the Whitehall Study were $17 \%$ and $13 \%$ and for the Regional Heart Study $32 \%$ and $31 \%$. An issue which must be considered in contrasting the electrocardiographic findings from these two studies with those of the Regional Heart Study concerns the sensitivity of the three lead orthogonal system compared with that of the 12 lead electrocardiogram. We have already indicated (see methods) that the orthogonal system requires less $\mathrm{ST}$ depression or $\mathrm{T}$ wave negativity for categorisation as myocardial ischaemia. Nevertheless, close comparison of the criteria used in the three lead and 12 lead systems indicates that all the categories of ischaemic heart disease (ECG) used in this presentation can be represented by an appropriate Minnesota Code. A factor which could account to a considerable extent for a lower prevalence of ischaemic heart disease in these other two studies is the "healthy worker" effect. ${ }^{28}$ Although men in the Whitehall Study were encouraged to attend regardless of whether or not they were currently under medical care, it is likely that those who suffered from ischaemic heart disease may have retired on medical grounds. Use of the limb leads only will lead to at least a $25 \%$ loss of information on myocardial ischaemia, and this loss is likely to be as high as $50 \%$ for Q : QS items. ${ }^{29}$ In the Whitehall Study, there is an unusual social class distribution, with social class III (manual) entirely unrepresented and with under-representation of social classes IV and V. ${ }^{30}$ This could also lead to some reduction in the prevalence of ischaemic heart disease in the study population.

The Whitehall Study is based on London, which has a low mortality rate for cardiovascular disease relative to Britain as a whole. The UKHDPP excludes the north of England and Scotland, which have relatively high mortality rates for cardiovascular disease. By contrast the Regional Heart Study includes men from all major geographic regions of Great Britain and adequately represents the social class composition of the male population. Only a very few men were excluded from the study by their general practitioners and the design of the study precludes the "healthy worker" effect seen in studies of occupational groups.

\section{HEART ATTACK REGISTERS}

Heart attack registers have been maintained in a number of countries over the past 10 years, including several registers in British towns. ${ }^{7831}$ These have provided valuable information on the frequency and natural history of heart attacks in different communities, and in particular have emphasised the prognostic importance of the previous history of cardiovascular disease. In the Tower Hamlets study in East London half of those suffering heart attacks had a previous history of ischaemic heart disease, and an appreciable minority were already unfit for work, mainly because of recognised cardiovascular disease. ${ }^{8}$

The WHO International Collaborative Study with heart attack registers in 19 European centres, as well as Australia (Perth) and Israel (Tel-Aviv), covered a population of 3.6 million men and women aged 20-64 years. ${ }^{32}$ In this study, two thirds of the men and four fifths of the women were already suffering from some form of cardiovascular disease by the time they experienced acute myocardial infarction or sudden death. The commonest preceding histories were hypertension, angina, and myocardial infarction.

The findings in the heart attack registers relate to the attempts we will make to determine the strength of the relations between risk factors and the frequency of ischaemic heart disease events. We have already noted in the Chicago epidemiological studies that electrocardiographic abnormalities have a relation to mortality independent of the established risk factors. ${ }^{21}$ There is also considerable evidence that the risk of death or recurrent myocardial infarction in those who have already experienced a myocardial infarction depends more on their age and the severity of the initial episode (manifest to some degree by the electrocardiographic changes) than on the level of the conventional risk factors such as smoking, hypertension, or raised serum cholesterol concentrations. ${ }^{33} 34$ These factors retain an independent effect but to a lesser extent than in those initially free of ischaemic heart disease.

\section{CONCLUSIONS}

The Regional Heart Study aims to explain the pronounced regional variations in cardiovascular disease mortality in Great Britain and to determine the causes 
of ischaemic heart disease. It is based on a survey of 7735 middle aged men recruited from general practices in 24 towns, and these men are being followed for morbidity and mortality over a five to 10 year period. The prognostic importance of their baseline personal characteristics will be determined by relating these potential "risk factors" to cardiovascular events taking place after the initial examination. In this report the criteria for determining the existence of ischaemic heart disease have been established, and the prevalence of ischaemic heart disease by these criteria has been presented. There is strong evidence from other studies that existing ischaemic heart disease is a potent risk factor for further episodes of ischaemic heart disease and that this may outweigh that associated with the conventional risk factors. Clearly, it is of paramount importance in the Regional Heart Study to categorise each subject by his previous/existing ischaemic heart disease as well as by determining his status for other personal and environmental risk factors. The prevalence criteria can be viewed as "risk factors" or as established ischaemic heart disease, and this dual possiblity emphasises the arbitrary nature of incidence in studies of this kind. In the Regional Heart Study we will be able to determine the relative risk of the many characteristics measured in subjects with a wide range of evidence of ischaemic heart disease. At the one extreme are those with definite myocardial infarction (ECG) plus possible myocardial infarction ( $Q$ ) and angina $(Q)$; at the other extreme are those with a normal electrocardiogram and no history of any chest pain. The relative risk of hypertension, cigarette smoking, or raised serum cholesterol concentrations in these extreme groups is likely to be different, and the determination of such relative risks is critical to a rational approach to the management and prevention of ischaemic heart disease.

The British Regional Heart Study is supported by a programme grant from the Medical Research Council. We deeply appreciate the dedicated work of the team of research nurses who carried out the survey and those members of the Regional Heart Study team responsible for the organisation and analysis of the data. Dr Nicholas Cohen, senior research fellow and codirector 1977-78, made considerable contribution to the design and development of the survey. Dr Stuart Pocock (statistician) and Dr Dag Thelle (Trömso, Norway, visiting epidemiologist) played an important role in the development of this paper. We also wish to thank the physiological measurement technicians in Glasgow who handled the ECG analysis and the medical physics technicians who serviced the ECG equipment. We are grateful to all the general practitioners and their staff for their willing collaboration.

\section{References}

1 Office of Population Censuses and Surveys. Mortality statistics, England and Wales 1981. London: HMSO, 1982.

2 Tunbridge WMG, Evered DC, Hale R, et al. Lipid profiles and cardiovascular disease in the Whickham area with particular reference to thyroid failure. Clin Endocrinol (Oxf) 1977; 7: 495-508.

3 Reid DD, Brett GZ, Hamilton PJS, Jarrett RJ, Keen H, Rose G. Cardiorespiratory disease and diabetes among middle-aged male civil servants. A study of screening and intervention. Lancet 1974; i: 469-73.

4 Fulton M, Adams W, Lutz W, Oliver MF. Regional variations in mortality from ischaemic heart disease and cerebrovascular disease in Britain. Br Heart F 1978; 40: 563-8.

5 Chilvers C, Adelstein AM. Interpreting patterns of mortality from circulatory disease in the regions of England and Wales: results from the Decennial Supplement on Area Mortality 1969-1973. Health Trends 1981; 13: 2831.

6 Marmot MG, Adelstein AM, Robinson N, Rose GA. Changing social-class distribution of heart disease. $\mathrm{Br}$ Med F 1978; ii: 1109-12.

7 Armstrong A, Duncan B, Oliver MF, et al. Natural history of acute coronary heart attacks. A community study. Br Heart f 1972; 34: 67-80.

8 Pedoe HT, Clayton D, Morris JN, Brigden W, McDonald L. Coronary heart attacks in East London. Lancet 1975; ii: 833-8.

9 Pocock SJ, Shaper AG, Cook DG, et al. British Regional Heart Study: geographic variations in cardiovascular mortality, and the role of water quality. $\mathrm{Br} M e d \mathrm{~F}^{1980}$; 280: 1243-9.

10 Shaper AG, Pocock SJ, Walker M, Cohen NM, Wale CJ, Thomson AG. British Regional Heart Study: cardiovascular risk factors in middle-aged men in 24 towns. $\mathrm{Br}$ Med f 1981; 283: 179-86.

11 Shaper AG, Cook DG, Walker M, Macfarlane PW. Recall of diagnosis by men with ischaemic heart disease. Br Heart f 1984; 51: 606-11.

12 Rose GA, Blackburn H, Gillum RF, Prineas RJ. Cardiovascular survey methods. 2nd ed. Geneva: World Health Organisation, 1982.

13 Macfarlane PW. A modified axial lead system for orthogonal lead electrocardiography. Cardiovasc Res 1969; 3: 510-5.

14 Macfarlane PW, Watts MP, Peden J, Lennox G, Lawrie TDV. Computer assisted ECG interpretation. British Fournal of Clinical Equipment 1976; 1: 61-70.

15 Macfarlane PW, Peden J, Lennox G, Watts MP, Lawrie TDV. The Glasgow system. In: van Bemmel JH, Williams JL, eds. Trends in computer processed electrocardiograms. Proceedings of the IFIP Working Conference. Amsterdam: North Holland, 1977: 143-50.

16 Macfarlane PW, Melville DI, Horton MR, Bailey JJ. Comparative evaluation of the IBM (12-lead) and the Royal Infirmary (orthogonal 3-lead) ECG computer programs. Circulation 1981; 63: 354-9.

17 Rose GA. The diagnosis of ischaemic heart pain and intermittent claudication in field surveys. Bull WHO 1962; 27: 645-58. 
18 Rose GA. Ischaemic heart disease. Chest pain questionnaire. Milbank Mem Fund $Q$ 1965; 43: 32-9.

19 Rose G. Variability of angina. Some implications for epidemiology. Br 7 Prev Soc Med 1968; 22: 12-15.

20 Pooling Project Research Group. Relationship of blood pressure, serum cholesterol, smoking habit, relative weight and ECG abnormalities to incidence of major coronary events: final report of the Pooling Project. $\mathcal{f}$ Chronic Dis 1978; 31: 201-306.

21 Cedres BL, Liu K, Stamler J, et al. Independent contribution of electrocardiographic abnormalities to risk of death from coronary heart disease, cardiovascular diseases and all causes. Findings of three Chicago epidemiology studies. Circulation 1982; 65: 146-53.

22 Blackburn H, Keys A, Simonson E, Rautaharju P, Punsar S. The electrocardiogram in population studies. A classification system. Circulation 1960; 21: 1160-75.

23 Pipberger HV, Lopez EA, Araoye MA, Pipberger HA. A new ECG classification system for epidemiologic investigations. In: de Padua F, Macfarlane PW, eds. New frontiers of electrocardiology. Chichester: Research Studies Press (John Wiley), 1981: 477-86.

24 Macfarlane PW, Chen CY, Hulton I, Lorimer AR. A comparison of 3 and 12 lead ECG $T$ wave changes in coronary artery disease. Fpn Heart $\mathcal{F}$ 1982; 23: 465-8.

25 Anonymous. Unrecognised myocardial infarction [Editorial]. Lancet 1976; ii: 449-50.

26 Rose G, Reid DD, Hamilton PJS, McCartney P, Keen
H, Jarrett RJ. Myocardial ischaemia, risk factors and death from coronary heart disease. Lancet 1977; i: 105-9.

27 WHO European Collaborative Group. Multifactorial trial in the prevention of coronary heart disease: 1 . Recruitment and critical findings. Eur Heart F 1980; 1: 73-80.

28 Goldsmith JR. What do we expect from an occupational cohort? FOM 1975; 17: 126-7.

29 Evans JG, Tunbridge WMG. Information loss in limblead electrocardiograms compared with twelve lead tracings in a population survey among the elderly. Age Ageing 1976; 5: 56-61.

30 Rose G, Marmot MG. Social class and coronary heart disease. Br Heart $\mathcal{F}$ 1981; 45: 13-9.

31 Colling A, Dellipiani AW, Donaldson RJ, MacCormack P. Teesside coronary survey: an epidemiological study of acute attacks of myocardial infarction. $\mathrm{Br} \mathrm{Med} \mathcal{F} 1976$; ii: 1169-72.

32 World Health Organisation. Myocardial infarction community registers. Copenhagen: WHO Regional Office for Europe, 1976.

33 Coronary Drug Project Research Group. Factors influencing long term prognosis after recovery from myocardial infarction-three year findings of the Coronary Drug Project. $f$ Chronic Dis 1974; 27: 267-85.

34 Mulcahy R, Hickey N, Graham I, McKenzie G. Factors influencing long-term prognosis in male patients surviving a first coronary attack. Br Heart $\mathcal{F} 1975 ; 37$ : 158-65. 